\title{
Removal of Chromium (VI) from Aqueous Solution Using Electro-Fenton Process
}

\author{
Ali reza Rahmani • Elham Hossieni • \\ Ali Poormohammadi
}

Received: 1 October 2014 / Accepted: 4 March 2015 / Published online: 2 May 2015

(C) Springer International Publishing Switzerland 2015

\begin{abstract}
Chromium (Cr) is considered to be mutagenic and carcinogenic, and is one of the most important pollutants that have been widely used in various industrial applications. Due to its adverse health impacts, $\mathrm{Cr}$ must be removed from effluents before being released into the water environments. The objective of the present study was to investigate the effect of electroFenton process (EFP) using iron electrodes in presence of sodium sulfate salt on the elimination of $\mathrm{Cr}(\mathrm{VI})$ from aqueous solution. The effect of various parameters such as $\mathrm{pH}$, voltage, initial $\mathrm{Cr}(\mathrm{VI})$ concentration, hydrogen peroxide dosage and cyanide concentration (as interference ion), on the process efficiency of $\mathrm{Cr}(\mathrm{VI})$ removal have also been tested. The results indicate that the optimum $\mathrm{pH}$, voltage and hydrogen peroxide dosage in EFP were determined to be $3,30 \mathrm{~V}$ and $50 \mathrm{~mL} / \mathrm{L}$, respectively. The results of this research also demonstrated that EFP efficiency decreased with increasing initial $\mathrm{Cr}(\mathrm{VI})$ concentration. Moreover, EFP efficiency $\mathrm{Cr}(\mathrm{VI})$ removal decreased with increasing cyanide concentration; accordingly, the cyanide acts as interference ion in EFP and can reduce the removal efficiency of $\mathrm{Cr}(\mathrm{VI})$. According to the obtained results, the maximum removal efficiency of $\mathrm{Cr}(\mathrm{VI})$ at optimum condition was $97 \%$ after $25 \mathrm{~min}$. These findings suggest that EFP is suitable option for removing $\mathrm{Cr}(\mathrm{VI})$ from aqueous solution.
\end{abstract}

Keywords Chromium (VI) $\cdot$ Electro-Fenton $\cdot$ Iron electrodes $\cdot$ Cyanide $\cdot$ Interference ion

\section{Introduction}

In recent years, the discharge of untreated industrial wastewater into the aquatic systems has become a major concern (Samarghandi et al. 2014). Industrial wastewater may contain a significant number of heavy metals (Di et al. 2006). Chromium $(\mathrm{Cr}$ ) is widely used in leather,

A. r. Rahmani $\cdot$ E. Hossieni

Department of Environmental Health, School of Public Health, Hamadan University of Medical Sciences, Hamadan, Iran

A. Poormohammadi $(\bowtie)$

Social Development \& Health Promotion Research Center, Kermanshah University of Medical Sciences,

Kermanshah, Iran

e-mail: apoormohammadi000@yahoo.com 
paint, petroleum, wood, electroplating and textile industries whose effluents are considered to be significant sources of $\mathrm{Cr}$. The most common forms of $\mathrm{Cr}$ found in the aquatic environment are $\mathrm{Cr}$ (III) and $\mathrm{Cr}(\mathrm{VI})$ (Hu et al. 2009). Trace amounts of $\mathrm{Cr}$ (III) are beneficial to human organisms as an essential micro-nutrient (Khazaei et al. 2011). By contrast, $\mathrm{Cr}(\mathrm{VI})$ is considered to be mutagenic and carcinogenic. In addition, strong exposure of $\mathrm{Cr}(\mathrm{VI})$ causes nausea, vomiting, severe diarrhea and hemorrhage. Also, $\mathrm{Cr}(\mathrm{VI})$ has been classified in the group 1 of carcinogen substances by the International Agency for Research on Cancer (IARC) (RomeroGonzález et al. 2006; Krishna and Siva Krishna 2013). The Environmental Protection Agency (EPA) has established $0.1 \mathrm{mg} / \mathrm{L}$ as maximum concentration of $\mathrm{Cr}$ in drinking water (Rafati et al. 2010). Due to various adverse effects of this compound, Cr (VI) must be treated before being released into the environment. It has been reported that $\mathrm{Cr}(\mathrm{VI})$ can be removed by chemical reduction, ion exchange, filtration, reverse osmosis and adsorption technology (Gao et al. 2005; Hasan et al. 2008; Baral et al. 2006). However, these technologies have some disadvantages, such as high reagent requirements, annual high operation costs, increased sludge production, costly adsorbent regeneration and clogging filter (Asgari et al. 2014; Malakootian et al. 2011). Therefore, alternative technologies have been developed to solve these problems. Nowadays, more and more attention has been paid to the use of electro-Fenton process (EFP) in treatment of various industrial wastewaters. In EFP, $\mathrm{H}_{2} \mathrm{O}_{2}$ is continuously generated on the cathode electrodes surface. The oxidizing power of the hydrogen peroxide is highly enhanced by the addition of $\mathrm{Fe}^{+2}$ generating from the Fenton reaction (Jiang and Mao 2012; Priambodo et al. 2011). In this process, $\mathrm{Fe}^{+2}$ or Fe ${ }^{+3}$ is added to the reactor solution to permit the oxidation of pollutants by hydroxyl radical generated from Fenton reaction according to Eq. (1). Moreover, $\mathrm{Fe}^{+3}$ can be reduced to $\mathrm{Fe}^{+2}$ according to Eq. (2) (Zarei et al. 2012; Bernardo-Bricker et al. 2014).

$$
\begin{gathered}
\mathrm{Fe}^{+2}+\mathrm{H}_{2} \mathrm{O}_{2}+\mathrm{H}^{+} \rightarrow \mathrm{Fe}^{+3}+\mathrm{OH}^{\circ}+\mathrm{H}_{2} \mathrm{O} \\
\mathrm{Fe}^{+3}+\mathrm{e}^{-} \rightarrow \mathrm{Fe}^{+2}
\end{gathered}
$$

On the other hand, in EFP metal precipitates play an important role in removing inorganic compounds. Previous studies demonstrated that EFP was an effective method for the removal of broad range of wastewater pollutants such as phenol, dye and other recalcitrant organic compounds (Zarei et al. 2012; Zhang et al. 2006). Accordingly, the present study explored EFP efficiency in $\mathrm{Cr}(\mathrm{VI})$ removal from aqueous solution as an inorganic substance. The effect of $\mathrm{pH}$, voltage, $\mathrm{H}_{2} \mathrm{O}_{2}$ and initial $\mathrm{Cr}(\mathrm{VI})$ concentration on the process efficiency were also investigated. Due to the fact that industrial wastewaters often contain different ions, from a practical point of view, in this research, the effect of various concentration of cyanide as an interference ion was also studied in relation to the performance of EFP in $\mathrm{Cr}(\mathrm{VI})$ removal.

\section{Materials and Methods}

\subsection{Materials}

Potassium dichromate $\left(\mathrm{K}_{2} \mathrm{Cr}_{2} \mathrm{O}_{7}\right.$, with a purity of $98 \%$ ), sodium cyanide $(\mathrm{NaCN}$, with a purity of $98.8 \%),\left(\mathrm{H}_{2} \mathrm{O}_{2}, 30 \%\right)$, sulfuric acid, hydroxide sodium, 1, 5-Diphenylcarbazide and sodium sulfate salt (98\%) were purchased from Merck and Sigma-Aldrich Co (Germany). 
To produce various amounts of voltage, a power supply device (SANJESH TEK, 8051, made of irannovin Co) was used. Moreover, solution $\mathrm{pH}$ was measured using a $\mathrm{pH}$ meter (Hatch Sinsion1). The samples were centrifuged using Centrifuge device (Sigma).

\subsection{The EFP System}

Experiments were carried out in a batch Plexiglas reactor with an effective volume of $1 \mathrm{~L}$. A sketch of the reactor is shown in Fig. 1. Iron was used as the electrodes material, placed in the reactor in a nonpolar mode (at a distance of $2 \mathrm{~cm}$ from each other). Two electrodes as anode and two other electrodes as cathodes were connected to the power supply device. Also, a magnetic stirrer was used to stir the contents of the reactor. According to submergence depth and electrode dimensions, the ratio of surface area of electrodes to reactor volume was equal to $3.2 \mathrm{~m}^{2} / \mathrm{m}^{3}$. All the experiments were performed at lab temperature.

\subsection{Experimental Procedure}

Potassium dichromate was used in preparing the $\mathrm{Cr}(\mathrm{VI})$ stock solution for all the experiments. Then, different initial concentrations of $\mathrm{Cr}(\mathrm{VI})$ were prepared by dissolving proper amounts of stock solution in distilled water. The effect of some parameters such as $\mathrm{pH}$, voltage, initial concentration of $\mathrm{Cr}(\mathrm{VI})$, hydrogen peroxide concentration and cyanide concentration as interference ion were studied on EFP. In the first step of experiments, the effect of $\mathrm{pH}$ on EFP efficiency was tested in the range 3-9. Solution $\mathrm{pH}$ of the samples was adjusted using hydroxide sodium $(1 \mathrm{~N})$ and sulfuric acid $(1 \mathrm{M})$. Finally, optimum $\mathrm{pH}$ was chosen. In the next step, experiments were performed under three voltage values (10, 20 and $30 \mathrm{~V})$. After determining optimum $\mathrm{pH}$ and voltage, the effect of initial $\mathrm{Cr}(\mathrm{VI})$ concentration on EFP efficiency was assessed in the range 100 to $1000 \mathrm{mg} / \mathrm{L}$. Moreover, in order to determine optimum concentration of hydrogen peroxide in EFP, various concentrations of hydrogen peroxide (in the range 10 to $100 \mathrm{~mL} / \mathrm{L}$ ) were tested under similar conditions. Finally, in order to determine the influence of cyanide as interference ion on EFP, experiments were carried out in absence and presence of cyanide at different concentrations in the range 100 to $500 \mathrm{mg} / \mathrm{L}$. Sodium sulfate salt $(500 \mathrm{mg} / \mathrm{L})$ has been added as supporting electrolytes in EFP to increase the electric current diffusion in the reactor. Also, samples were withdrawn from the middle of the reactor at time intervals of 5, 10, 15, 20 and $25 \mathrm{~min}$. All analyses were conducted in duplicate.

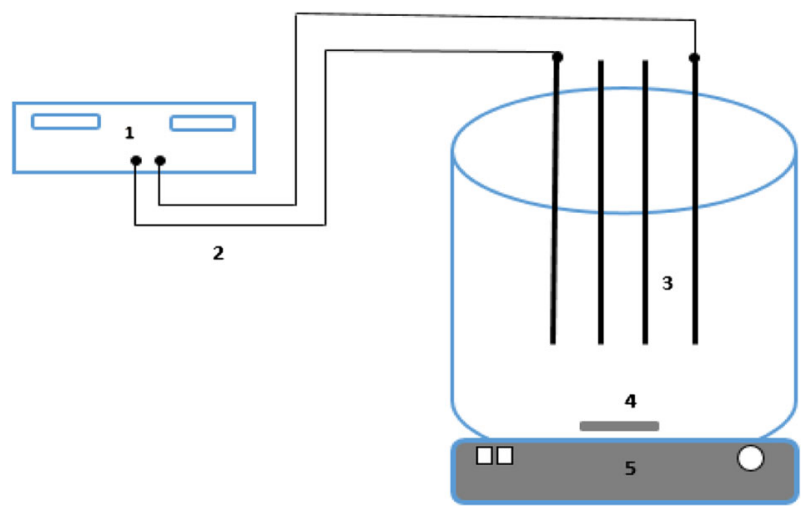

Fig. 1 EF reactor schematic: 1. Power supply; 2. Wires; 3. Iron electrodes; 4. Magnet; 5. Stirrer 


\subsection{Analysis}

$\mathrm{Cr}(\mathrm{VI})$ concentrations were measured by 1, 5-diphenylcarbazide method using UV-visible spectrophotometer (DR 5000) at $540 \mathrm{~nm}$ wave length. In order to avoid the effect of interference agents such as residual iron in the samples and produced sludge, all samples were centrifuged for $3 \mathrm{~min}(4000 \mathrm{rpm}$ ) using Centrifuge device (Hasan et al. 2008; Anota et al. 2006; Pazos et al. 2010). The Cr(VI) removal was determined by the following Eq. (3):

$$
\mathrm{Cr}(\mathrm{VI}) \text { removal } \%=\frac{C_{0}-C}{C_{0}} \times 100
$$

where $\mathrm{C}_{0}$ and $\mathrm{C}$ are $\mathrm{Cr}(\mathrm{VI})$ concentration $(\mathrm{mg} / \mathrm{L})$ before and after experiments, respectively.

\section{Results and Discussion}

\subsection{Effect of $\mathrm{pH}$}

The initial $\mathrm{pH}$ of the solution is one of the most important factors in EFP. In the present study, the effect of $\mathrm{pH}$ in EFP on $\mathrm{Cr}(\mathrm{VI})$ removal was studied in the range 3-9. As shown in Fig. 2a,
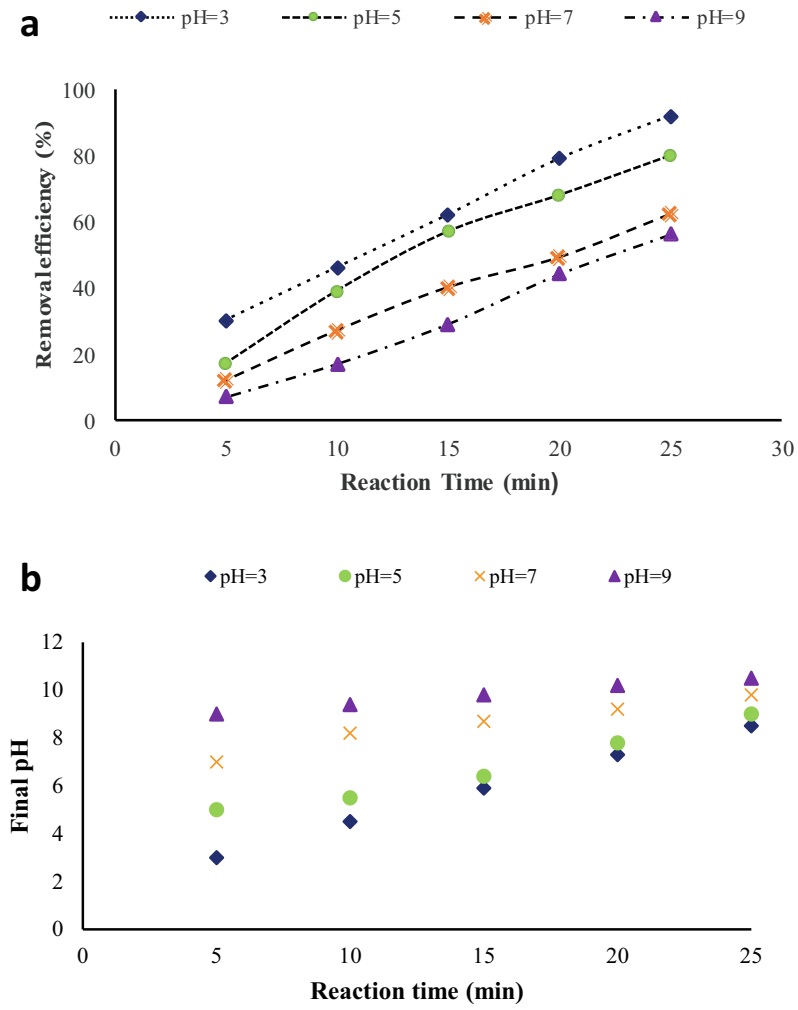

Fig. 2 a The effect of solution initial $\mathrm{pH}$ on the EF process efficiency $\mathbf{b}$ The final $\mathrm{pH}$ values of the solution during the EF process (Voltage: $20 \mathrm{~V}$, initial Cr VI concentration: $100 \mathrm{mg} / \mathrm{L}, \mathrm{H}_{2} \mathrm{O}_{2}: 25 \mathrm{~mL} / \mathrm{L}$, electrolyte concentration: $0.5 \mathrm{~g} / \mathrm{L}$ of sodium sulfate) 
the EFP efficiency decreased with increasing $\mathrm{pH}$. The maximum removal efficiency was achieved at $\mathrm{pH}$ 3. This is attributed to the role of $\mathrm{pH}$ on EFP, because in this process main species like $\mathrm{Fe}(\mathrm{OH})^{+2}\left(\mathrm{H}_{2} \mathrm{O}\right)_{5}$ at strong acidic conditions have the largest light absorption coefficient (Zarei et al. 2010; Priambodo et al. 2011). Also, at strong acidic conditions, sodium sulfate salt yield sulfate ions; sulfate and $\mathrm{Fe}^{2+}$ ions in $\mathrm{EFP}$ can cause reduction of $\mathrm{Cr}(\mathrm{VI})$ to $\mathrm{Cr}$ (III). Therefore, the EFP using iron electrodes can cause first the reduction of $\mathrm{Cr}(\mathrm{VI})$ to $\mathrm{Cr}$ (III), and then, removal the total $\mathrm{Cr}$ (III) from the water solution through precipitation (Souza et al. 2012). This finding is consistent with the results of many authors about optimum $\mathrm{pH}$ range in EFP (e.g., Jiang and Mao 2012; Priambodo et al. 2011). Moreover, some previous studies revealed that the values of $\mathrm{pH}$ in Fenton oxidation should be in the range 2 to 4 (Priambodo et al. 2011; Zhang et al. 2006). Therefore, in the present study, $\mathrm{pH}$ of 3 was chosen as the optimum condition in the following experiments. In addition, the final $\mathrm{pH}$ values of the solution were measured during the reaction. As can be observed in Fig. 2b, the $\mathrm{pH}$ values increased with increasing reaction time; the increase in solution $\mathrm{pH}$ may be beneficial for the coagulation of the precipitates of $\mathrm{Cr}(\mathrm{OH})_{3}$ and $\mathrm{Fe}(\mathrm{OH})_{3}$.

\subsection{Effect of Applied Voltage}

One of the other important factors in EFP is the applied voltage, because the hydrogen peroxide generation in this process is directly related to the applied voltage. In the present study, the effect of various voltage values on EFF efficiency was studied. Figure 3, shows the efficiency of removing $\mathrm{Cr}(\mathrm{VI})$ for electrical potential values of 10,20 and $30 \mathrm{~V}$ and $\mathrm{pH}$ of 3. As shown in Fig. 3, the maximum removal efficiency of Cr(VI) by EFP was equal to $95 \%$ and was achieved at voltage of $30 \mathrm{~V}$ after $25 \mathrm{~min}$. According to the results, the EFP efficiency increased with the increase of the applied voltage. This increase in the removal efficiency can be attributed to the fact that in EFP the electro-regeneration of iron ions increased with the increasing applied voltage. Consequently, $\mathrm{Cr}(\mathrm{VI})$ may be reduced to $\mathrm{Cr}$ (III) by means of $\mathrm{Fe}^{2+}$ ions, then $\mathrm{Cr}$ (III) can be removed by the coagulation of the precipitates of $\mathrm{Cr}(\mathrm{OH})_{3}$ and $\mathrm{Fe}(\mathrm{OH})_{3}$ (Souza et al. 2012). Moreover, by increasing the applied voltage, a higher rate of hydroxyl radicals are generated by the degradation of hydrogen peroxide (Samarghandi et al. 2014); the increase in hydrogen peroxide concentration will be beneficial for the coagulation of the precipitates of $\mathrm{Cr}(\mathrm{OH})_{3}$ and $\mathrm{Fe}(\mathrm{OH})_{3}$ (Souza et al. 2012). Also, similar results were obtained by Jiang and Mao (2012) on the removal of phenol using EFP, however, the results of

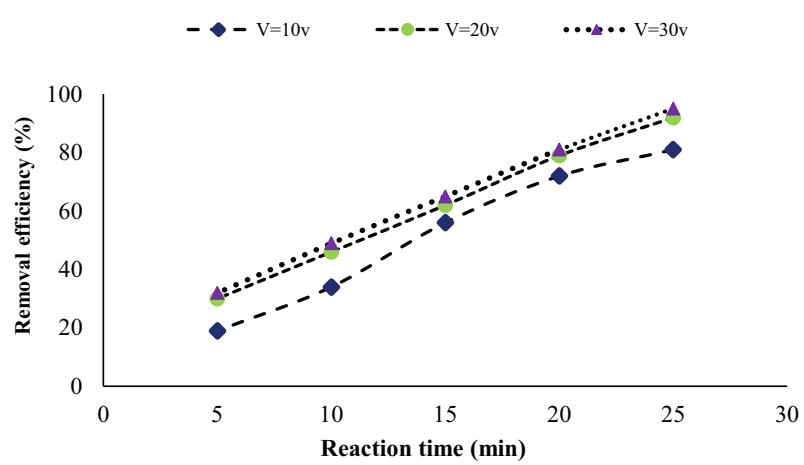

Fig. 3 The effect of voltage on the EF process efficiency (pH: 3, initial $\mathrm{Cr}(\mathrm{VI})$ concentration: $100 \mathrm{mg} / \mathrm{L}, \mathrm{H}_{2} \mathrm{O}_{2}$ : $25 \mathrm{~mL} / \mathrm{L}$, electrolyte concentration: $0.5 \mathrm{~g} / \mathrm{L}$ of sodium sulfate) 
the mentioned study indicated that further increase of the electrical current led to decrease in the COD removal efficiency (Priambodo et al. 2011).

\subsection{Effect of Hydrogen Peroxide}

In this part of the study, the effect of hydrogen peroxide dosage $(10,25,50,75$ and $100 \mathrm{~mL} / \mathrm{L})$ on EFP was investigated. As revealed in Fig. 4, in EFP the maximum removal efficiency of $\mathrm{Cr}(\mathrm{VI})$ in presence of 25 and $50 \mathrm{~mL} / \mathrm{L}$ of hydrogen peroxide was 95 and $97 \%$, respectively. On the contrary, the minimum removal efficiency was obtained at 10 and $100 \mathrm{~mL} / \mathrm{L}$ of hydrogen peroxide, which was 76 and $72 \%$, respectively. Therefore, in EFP with the increase of hydrogen peroxide from 10 to $50 \mathrm{~mL} / \mathrm{L}$, the process efficiency in removal of $\mathrm{Cr}(\mathrm{VI})$ was enhanced. This can be related to the increase of hydrogen peroxide concentration. According to Eq. (1), the presence of hydrogen peroxide in EFP can lead to a faster production of $\mathrm{Fe}^{3+}$. On the other hand, when an iron anode is used in EFP, $\mathrm{Fe}^{2+}$ is dissolved in the reactor from the iron anode electrode, whereas hydroxide ions and $\mathrm{H}_{2}$ gas are generated at the cathode according to Eq. 4 (Souza et al. 2012; Seid-Mohammadi et al. 2014):

$$
2 \mathrm{H}_{2} \mathrm{O}+2 \mathrm{e}^{\circ} \rightarrow 2 \mathrm{OH}^{\circ}+\mathrm{H}_{2}
$$

In the presence of $\mathrm{O}_{2}$, dissolved $\mathrm{Fe}^{2+}$ is oxidized to $\mathrm{Fe}(\mathrm{OH})_{3}$, according to the Eq. 5(Souza et al. 2012):

$$
4 \mathrm{Fe}^{2+}+10 \mathrm{H}_{2} \mathrm{O}+\mathrm{O}_{2} \rightarrow 4 \mathrm{Fe}(\mathrm{OH})_{3}+8 \mathrm{H}^{+}
$$

Once the insoluble flock of $\mathrm{Fe}(\mathrm{OH})_{3}$ are produced, they can remove Cr by surface attraction (Souza et al. 2012; Seid-Mohammadi et al. 2014). Consequently, the Cr(VI) removal efficiency by EFP increases. In contrast, as the hydrogen peroxide dosage increase from 50 to $100 \mathrm{~mL} /$ $\mathrm{L}$, the process efficiency decreased. This result is due to over-dosage of hydrogen peroxide in the reactor, which can lead to the faster consumption of hydrogen peroxide. Finally, the hydroperoxyl radical generated from the hydrogen peroxide decomposition (according to Eq. 6), is a weak oxidant compared with the hydroxyl radical (Zarei et al. 2012).

$$
\mathrm{OH}^{\circ}+\mathrm{H}_{2} \mathrm{O}_{2} \rightarrow \mathrm{H}_{2} \mathrm{O}+\mathrm{HO}_{2}^{\circ}
$$

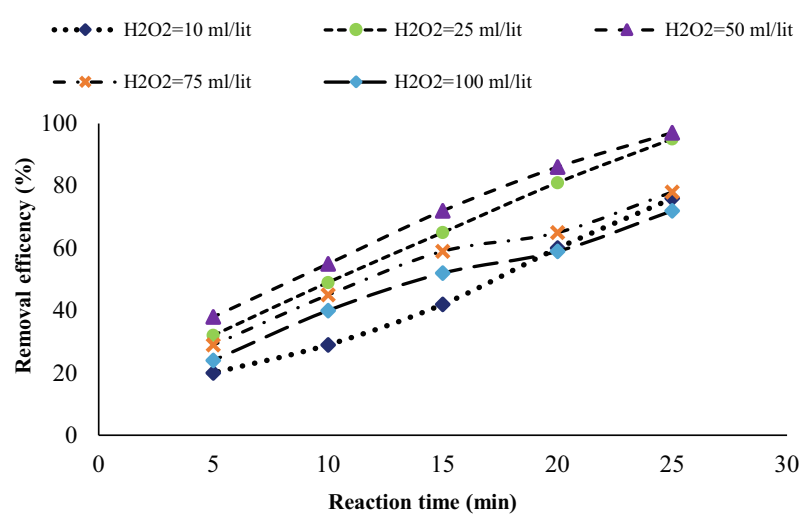

Fig. 4 The effect of hydrogen peroxide dosage on the EF process efficiency (pH: 3, voltage: $30 \mathrm{~V}$, initial Cr(VI) concentration: $100 \mathrm{mg} / \mathrm{L}$, electrolyte concentration: $0.5 \mathrm{~g} / \mathrm{L}$ of sodium sulfate) 


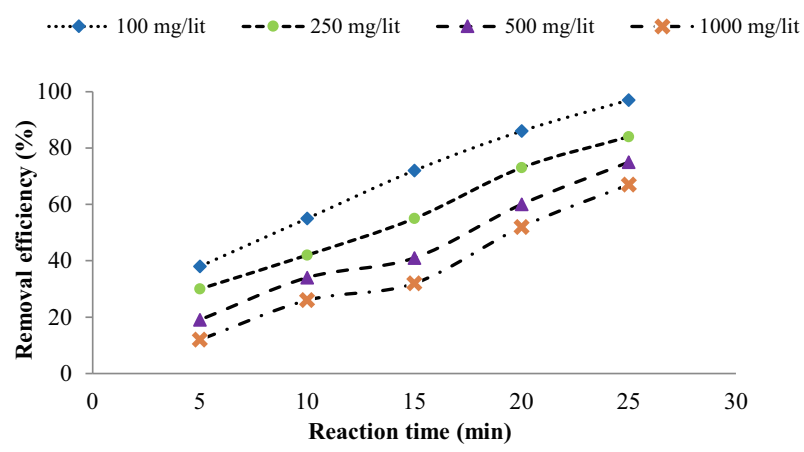

Fig. 5 The effect of initial $\mathrm{Cr}(\mathrm{VI})$ concentration on the EF process efficiency (pH: 3, voltage: $30 \mathrm{~V}, \mathrm{H}_{2} \mathrm{O}_{2}$ : $50 \mathrm{~mL} / \mathrm{L}$, electrolyte concentration: $0.5 \mathrm{~g} / \mathrm{L}$ of sodium sulfate)

\subsection{Effect of Initial Cr(VI) Concentration}

Due to the fact that industrial wastewaters often contain various concentration of pollutants, in this step of experiments, the effect of different initial concentrations of $\mathrm{Cr}(\mathrm{VI})$ on EFP were studied. Figure 5 presents EFP efficiencies at different initial concentrations of $\mathrm{Cr}(\mathrm{VI})$, e.g., $100,250,500$ and $1000 \mathrm{mg} / \mathrm{L}$. The results indicate that the removal efficiencies of 100 and $1000 \mathrm{mg} / \mathrm{L} \mathrm{Cr}(\mathrm{VI})$ were 97 and $67 \%$ after $25 \mathrm{~min}$, respectively. So, the efficiency of EF process decreased with increasing $\mathrm{Cr}(\mathrm{VI})$ concentration. This can be attributed to this fact that EFP produced only a limited amount of coagulant agents and hydroxyl radicals, thus the removal efficiency reduced with the increase of $\mathrm{Cr}(\mathrm{VI})$ concentration. This result is in accordance with the findings on Fe (III) removal by Ghosh et al. (2003). Seid-Mohammadi et al. (2014) also observed that in the electrocoagulation process using iron electrode, as the initial concentration of humic acid increased, its removal efficiency decreased.

\subsection{Effect of Interference Ion}

Cyanide is one of the most toxic substances found in industrial wastewater such as gold extraction, metallurgical, coal power, petrochemical, oil, paint, photography, iron and steel industries. Therefore, most of industrial wastewaters can contain different concentrations of

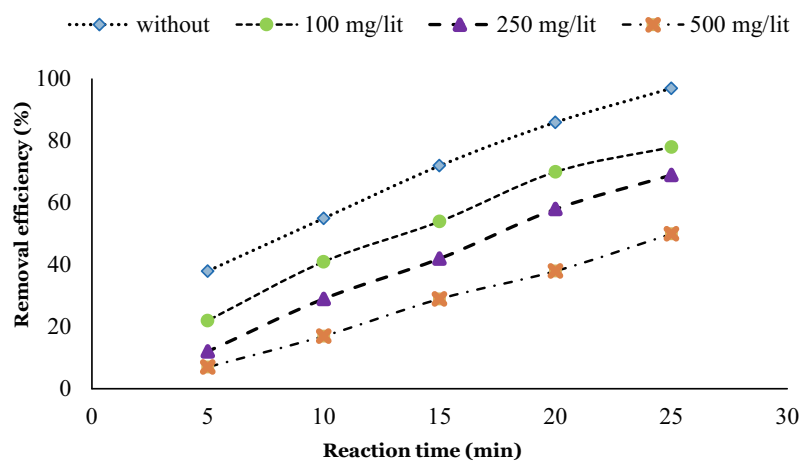

Fig. 6 The effect of initial cyanide concentration on the EF process efficiency (pH: 3, voltage: $30 \mathrm{~V}, \mathrm{H}_{2} \mathrm{O}_{2}$ : $50 \mathrm{~mL} / \mathrm{L}$, initial Cr VI concentration: $100 \mathrm{mg} / \mathrm{L}$, electrolyte concentration: $0.5 \mathrm{~g} / \mathrm{L}$ of sodium sulfate) 
Table 1 The parameters obtained from various kinetics models using different $\mathrm{Cr}(\mathrm{VI})$ concentrations

\begin{tabular}{|c|c|c|c|c|c|c|}
\hline \multirow{2}{*}{$\begin{array}{l}\text { Initial Cr(VI) } \\
\text { concentration }(\mathrm{mg} / \mathrm{L})\end{array}$} & \multicolumn{2}{|c|}{ Zero-order } & \multicolumn{2}{|c|}{ First-order } & \multicolumn{2}{|c|}{ Second-order } \\
\hline & $\mathrm{k}_{0}$ & $\mathrm{R}^{2}$ & $\mathrm{k}_{1}$ & $\mathrm{R}^{2}$ & $\mathrm{k}_{2}$ & $\mathrm{R}^{2}$ \\
\hline 100 & 14.9 & 0.99 & 0.72 & 0.90 & $1.3 \times 10^{-3}$ & 0.85 \\
\hline 250 & 34.7 & 0.99 & 0.37 & 0.95 & $4.6 \times 10^{-3}$ & 0.85 \\
\hline 500 & 69 & 0.98 & 0.28 & 0.93 & $5 \times 10^{-4}$ & 0.87 \\
\hline 1000 & 136 & 0.97 & 0.23 & 0.93 & $6.8 \times 10^{-2}$ & 0.64 \\
\hline
\end{tabular}

cyanide, which can affect the treatment process. In this research, to study the effect of cyanide ion on EFP efficiency in removal of $\mathrm{Cr}(\mathrm{VI})$, experiments were performed at various concentrations of cyanide $(100,250$ and $500 \mathrm{mg} / \mathrm{L})$ as an interference ion. The results are shown in Fig. 6. As shown, the maximum removal efficiency of $\mathrm{Cr}(\mathrm{VI})$ was obtained in absence of cyanide. The results also indicate that the EFP efficiency in $\mathrm{Cr}(\mathrm{VI})$ removal decreases with increasing cyanide concentration, with removal efficiency of $\mathrm{Cr}(\mathrm{VI})$ for cyanide concentrations of 100,250 and $500 \mathrm{mg} / \mathrm{L}$ being 78, 69 and $50 \%$, respectively, after $25 \mathrm{~min}$. Thus, it is concluded that the presence of cyanide ions has adverse impact on EFP efficiency and can reduce the removal efficiency of $\mathrm{Cr}(\mathrm{VI})$ by this process. This can be associated to the fact that in EFP the hydroxyl radicals produced by decomposition of hydrogen peroxide react with cyanide, so this phenomenon leads to increase in oxidation of cyanide and reduction of EFP efficiency in Cr(VI) removal (Jiang and Mao 2012; Asgari et al. 2014). Xue et al. (2008) also observed that the presence of anions in the adsorption process has inhabitant effects on adsorption of dye. There are no another similar published studies which can be compared with this part of our findings.

\subsection{Kinetic Study}

In this study, the kinetics of $\mathrm{Cr}(\mathrm{VI})$ removal using EFP were also investigated to select the optimum conditions for greater scales. Therefore, to achieve this goal, zero-order, first-order and second-order kinetics were investigated.

The results obtained revealed that the removal process followed the zero-order kinetic model with a correlation coefficient values of 0.99 (Table 1). Fig. 7 shows the kinetic curves

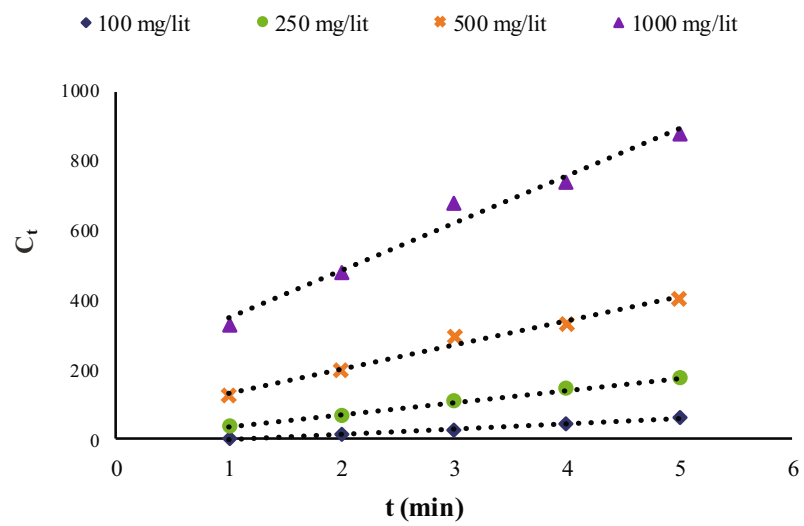

Fig. 7 The results of kinetic study (zero-order kinetic model) 
obtained from zero models. Therefore, the zero-order kinetic model gave better results than other models in removal of $\mathrm{Cr}(\mathrm{VI})$ using EFP. The reaction is very likely to take place on the surface of the electrode. Therefore, zero order is observed.

\section{Conclusion}

The present study has explored the efficiency of EFP in removal of $\mathrm{Cr}(\mathrm{VI})$ from synthetic wastewater. The effect of $\mathrm{pH}$, voltage, $\mathrm{H}_{2} \mathrm{O}_{2}$ and initial $\mathrm{Cr}(\mathrm{VI})$ concentration were tested. The results indicated that, the optimum $\mathrm{pH}$, voltage and hydrogen peroxide dosage in EFP were 3, $30 \mathrm{~V}$ and $50 \mathrm{~mL} / \mathrm{L}$, respectively. The results also demonstrated that the EFP efficiency decreased with the increasing initial $\mathrm{Cr}(\mathrm{VI})$ concentration. Moreover, the EFP efficiency in $\mathrm{Cr}(\mathrm{VI})$ removal decreased with increasing cyanide concentration, accordingly cyanide acts as interference ion in EFP and can reduce the removal efficiency of $\mathrm{Cr}(\mathrm{VI})$. The results of the kinetic study indicated that the zero-order kinetic model gave better results than other models in removal of $\mathrm{Cr}(\mathrm{VI})$ using EFP. Based on the results obtained, EFP is a suitable option in removing $\mathrm{Cr}(\mathrm{VI})$ from an aqueous solution.

Acknowledgments Elham Hossieni carried out the experiments and Dr. Ali Reza Rahmani participated in the design. Other implementation of this research work including data analysis, design and manuscript preparation were the results of the corresponding author's efforts. The authors would like to thank Hamadan University of Medical Science for the financial support of this project.

\section{References}

Anota J, Lu MC, Chewpreech P (2006) Kinetics of aniline degradation by Fenton and Electro-Fenton processes. Water Res 40:1841-1847

Asgari G, Seid Mohammadi AM, Poormohammadi A, Ahmadian M (2014) Removal of cyanide from aqueous solution by adsorption onto bone charcoal. Fresenius Environ Bull 23(3):720-727

Baral SS, Das SN, Rath P (2006) Hexavalent chromium removal from aqueous solution by adsorption on treated sawdust. Biochem Eng J 31(3):216-222

Bernardo-Bricker AR, Singh SK, Trovó AG, Tang WZ, Tachiev G (2014) Biodegradability enhancement of mature landfill leachate using Fenton process under different COD loading factors. Environ Process 1(3): 207-219

Di ZC, Ding J, Peng XJ, Li YH, Luan ZK, Liang J (2006) Chromium adsorption by aligned carbon nanotubes supported ceria nanoparticles. Chemosphere 62:861-865

Gao P, Chen X, Shen F, Chen G (2005) Removal of chromium (VI) from wastewater by combined electrocoagulation-electroflotation without a filter. Sep Purif Technol 43:117-123

Ghosh UC, Dasgupta M, Debnath S, Bhat SC (2003) Studies on management of chromium (VI)contaminated industrial waste effluent using hydrous titanium oxide (HTO). Water Air Soil Pollut $143: 245-256$

Hasan SH, Singh KK, Prakash O, Talat M, Ho YS (2008) Removal of Cr(VI) from aqueous solutions using agricultural waste maize bran. J Hazard Mater 152:356-365

Hu J, Wang SW, Shao DD, Dong YH, Li JX, Wang XK (2009) Adsorption and reduction of chromium (VI) from aqueous solution by multi-walled carbon nanotubes. Open Environ Pollut Toxicol J 1:66-73

Jiang L, Mao X (2012) Degradation of phenol-containing wastewater using an improved Electro-Fenton process. Int J Electrochem Sci 7:4078-4088

Khazaei I, Aliabadi M, Hamed Mosavian HT (2011) Use of agricultural waste for removal of Cr(VI) from aqueous solution. Iran J Chem Eng 8(4):11-23

Krishna D, Siva Krishna K (2013) Removal of chromium from aqueous solution by borasus flabellifer coir powder as adsorbent. Elixir Chem Engg 56:13308-13317 
Malakootian M, Fatehizadeh A, Yousefi N, Ahmadian M, Moosazadeh M (2011) Fluoride removal using regenerated spent bleaching earth (RSBE) from groundwater: case study on kuhbonan water. Desalination 277:244-249

Pazos M, Branco M, Neves IC, Sanromán MA, Tavares T (2010) Removal of Cr(VI) from aqueous solutions by a bacterial biofilm supported on zeolite: optimisation of the operational conditions and scale-up of the bioreactor. Chem Eng Technol 33(12)

Priambodo R, Shih YJ, Huang YJ, Huang YH (2011) Treatment of real wastewater using semi batch (Photo)Electro-Fenton method. Sustain Environ Res 21(6):389-393

Rafati L, Mahvi AH, Asgari AR, Hosseini SS (2010) Removal of chromium (VI) from aqueous solutions using Lewatit FO36 Nano ion exchange resin. Int J Environ Sci Technol 7(1):147-156

Romero-González J, Peralta-Videa JR, Rodri'guez E, Delgado M, Gardea-Torresde JL (2006) Potential of Agave lechuguilla biomass for $\mathrm{Cr}$ (III) removal from aqueous solutions: Thermodynamic studies. Bioresour Technol 97:178-182

Samarghandi MR, Ahmadian M, Mehralipur J, Shabanlo A, Poormohammadi A (2014) Studies on removal of cyanide from aqueous environments using aluminum electrodes. Fresenius Environ Bull 23(2a):613-619

Seid-Mohammadi AM, Asgari G, Samadi MT, Ahmadian M, Poormohammadi A (2014) Removal of humic acid from synthetic water using chitosan as coagulant aid in electrocoagulation process for $\mathrm{Al}$ and $\mathrm{Fe}$ electrodes. Res J Chem Environ 18(5):19-25

Souza KR, Silva DR, Mata W, Martínez-Huitle CA, Mata ALML (2012) Electrochemical technology for removing heavy metals present in synthetic produced water. Lat Am Appl Res 42:141-147

Xue SW, Yin Z, Yu J, Cheng (2008) The removal of basic dyes from aqueous solutions using agricultural byproducts. J Hazard Mater 157(19):374-385

Zarei M, Niaei A, Salari D, Khataee AR (2010) Removal of four dyes from aqueous medium by the peroxicoagulation method using carbon nanotube-PTFE cathode and neural network modeling. J Electroanal Chem 639:167-174

Zarei M, Khataee A, Fathinia M, Seyyednajafi F, Ranjbar H (2012) Combination of nanophotocatalysis with electro-Fenton-like process in the removal of phenol from aqueous solution: GC analysis and response surface approach. Int J Ind Chem 3(27):2-11

Zhang H, Zhang DB, Zhou JY (2006) Removal of COD from landfill leachate by electro-Fenton method. J Hazard Mater 135(1-3):106-111 